\title{
Pandemic Self-Medication: Care in the Use of Ansiolytics and Antidepressants by Brazilians
}

\author{
Julio CP Souza* \\ Faculdade Metropolitana de Manaus, University Center Fametro, Brazil \\ *Corresponding author: Julio CP Souza, Faculdade Metropolitana de Manaus, University Center Fametro, Brazil
}

\begin{tabular}{|c|c|}
\hline ARTICLE INFO & ABSTRACT \\
\hline Received: 慧 August 28, 2021 & $\begin{array}{l}\text { Citation: Julio CP Souza. Pandemic Self-Medication: Care in the Use of Ansiolytics and } \\
\text { Antidepressants by Brazilians. Biomed J Sci \& Tech Res 38(4)-2021. BJSTR. MS.ID.006192. }\end{array}$ \\
\hline
\end{tabular}

\section{Mini Review}

COVID-19 has forced Brazilian population to drastically change their routine at home, at work and even in social interactions. The fear and insecurity that the Pandemic brought to Brazilian population has had a negative impact on the mental health of Brazilians. According to Afonso and Figueira (2020) [1], the long period of social distancing and submission to the restrictive measures imposed to control Pandemic, led to the appearance of clinical condition of depression and anxiety and the abuse of substances such as alcohol, anxiolytics and hypnotics. As a result of the increase of cases of psychiatric disorders, the sale and consumption of controlled medications increased significantly, as presented by Tiago Américo (2021) [2] that in 2020, almost 100 million boxes of controlled medications were sold. Comparing the data with the previous year, there was an increase of $17 \%$ in sales of these drugs, the states of Amazonas and Ceará lead the consumption of antidepressants. It is noteworthy that these drugs are controlled drugs, that is, anxiolytics and antidepressants should be sold only with a medical prescription, considering the danger that these drugs offer to users, in view of their side effects and drug interactions that they have. These psychotropic drugs have several side effects (effects caused by the medication different from those expected), among which we can mention the loss of motor coordination, drowsiness, lack of concentration and dizziness. These effects can vary from person to person, causing that some have many unwanted symptoms with the use of a medication and others have no symptoms at all. To establish which anxiolytic and / or antidepressant will be used by the patient, the doctor performs a detailed evaluation in order to prescribe the medication that best meets the needs and characteristics of the patients, in addition to passing a series of guidelines on the care to be taken. Considering the serious implications of their use, it is easy to understand that these drugs cannot be used indiscriminately. Due to the panic caused by social distancing and the transmission, by the media, of alarming and tragic news, self-medication during the Pandemic period was significantly accentuated (Silva, Ponciano \& Luz, 2020) [3]. Among the practices of self-medication by Brazilian society, observed in Pandemic, the use of psychotropic drugs, in particular anxiolytics and antidepressants, draws attention. Despite the prohibition of the sale of anxiolytics and antidepressants without a medical prescription, many Brazilians acquire these drugs, by different ways, making use of them in an uncontrolled and abusive manner. The consumption of psychiatric drugs without medical supervision is a great danger, since the indiscriminate use of anxiolytics and / or antidepressants, commonly leads the user to addiction, leaving him vulnerable to withdrawal crises (when he does not have the medicine). Prolonged consumption without guidance can still lead the individual to tolerance to medications. Dalgalarrondo (2019) explains that this pharmacological phenomenon arises from the body's need to receive higher doses of the substance to obtain the desired effects. He also comments that drugs such as benzodiazepines (base of anxiolytics) frequently present this phenomenon. Another danger of self-medication with anxiolytics and antidepressants is the existence of drug interactions (the ingestion of two or more drugs, not necessarily at the same time) 
that can cause changes in thinking, lowering of consciousness, vomiting, convulsion and in extreme cases lead to another type of very dangerous but often encountered interaction is the use of anxiolytics with alcoholic beverages. This association of depressant substances leads to a potentiating of the medication's sedative effect, which can cause respiratory failure and lead to coma (CRF/ SP, 2012). Based on these questions, it is understood that this issue is relevant for the clarification of society, as it becomes a public health issue and that everyone reflects on the following message: "anxiolytics and antidepressants should only be used, with medical prescription and the existence of clinical conditions diagnosed by a specialized and qualified professional" [4].

\section{ISSN: 2574-1241}

DOI: $10.26717 /$ BJSTR.2021.38.006192

Julio CP Souza. Biomed J Sci \& Tech Res

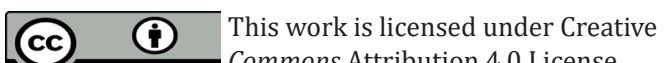

Submission Link: https://biomedres.us/submit-manuscript.php

\section{Competing Interests}

None.

\section{References}

1. Afonso, Pedro, Figueira, Maria Luísa (2020) Pandemia COVID-19: Quais são os Riscos para a Saúde Mental? Revista portuguesa de psiquiatria e saúde mental. 6 (1): 2-3.

2. Américo, Tiago (2021) Venda de antidepressivos cresce $17 \%$ durante pandemia no Brasil. São Paulo. 23 de fevereiro de 2021.

3. Silva Carla Yasmin Alves Batista, Ponciano Anna Karollayne Bezerra, Luz Dayse Christina Rodrigues Pereira (2020) Automedicação durante a pandemia da covid-19. Rev. e-ciência 8(2): 1-2.

4. (2012) Conselho Regional de Farmácia. Álcool X medicamentos.

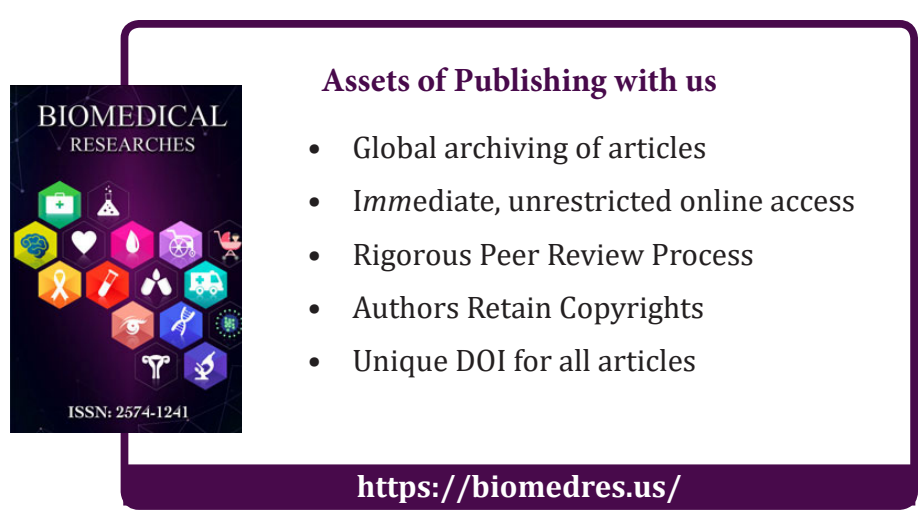

